\title{
Validation of a global satellite rainfall product for real time monitoring of meteorological extremes
}

Fulgencio Cánovas-García, Sandra García-Galiano, Negar Karbalaee

Fulgencio Cánovas-García, Sandra García-Galiano, Negar Karbalaee, "Validation of a global satellite rainfall product for real time monitoring of meteorological extremes," Proc. SPIE 10421, Remote Sensing for Agriculture, Ecosystems, and Hydrology XIX, 1042109 (2 November 2017); doi: $10.1117 / 12.2278398$

SPIE. Event: SPIE Remote Sensing, 2017, Warsaw, Poland 


\title{
Validation of a global satellite rainfall product for real time monitoring of meteorological extremes
}

\author{
Fulgencio Cánovas-García ${ }^{\mathrm{a}}$, Sandra García-Galiano ${ }^{\mathrm{b}}$, and Negar Karbalaee ${ }^{\mathrm{c}}$ \\ ${ }^{a}$ Department of Civil Engineering, Universidad Politécnica de Cartagena, Paseo Alfonso XIII, \\ 52 30203, Cartagena, Spain \\ ${ }^{\mathrm{b}}$ Department of Civil Engineering, Universidad Politécnica de Cartagena, Paseo Alfonso XIII, \\ 52 30203, Cartagena, Spain \\ ${ }^{\mathrm{c}}$ Center for Hydrometeorology and Remote Sensing (CHRS), Civil and Environmental \\ Engineering Department, University of California Irvine, USA
}

\begin{abstract}
The real time monitoring of storms is important for the management and prevention of flood risks. However, in the southeast of Spain, it seems that the density of the rain gauge network may not be sufficient to adequately characterize the rainfall spatial distribution or the high rainfall intensities that are reached during storms. Satellite precipitation products such as PERSIANN-CCS (Precipitation Estimation from Remotely Sensed Information using Artificial Neural Networks - Cloud Classification System) could be used to complement the automatic rain gauge networks and so help solve this problem. However, the PERSIANN-CCS product has only recently become available, so its operational validity for areas such as south-eastern Spain is not yet known. In this work, a methodology for the hourly validation of PERSIANN-CCS is presented. We used the rain gauge stations of the SIAM (Sistema de Información Agraria de Murcia) network to study three storms with a very high return period. These storms hit the east and southeast of the Iberian Peninsula and resulted in the loss of human life, major damage to agricultural crops and a strong impact on many different types of infrastructure. The study area is the province of Murcia (Region of Murcia), located in the southeast of the Iberian Peninsula, covering an area of more than $11,000 \mathrm{~km}^{2}$ and with a population of almost 1.5 million. In order to validate the PERSIANN-CCS product for these three storms, contrasts were made with the hyetographs registered by the automatic rain gauges, analyzing statistics such as bias, mean square difference and Pearson's correlation coefficient. Although in some cases the temporal distribution of rainfall was well captured by PERSIANN-CCS, in several rain gauges high intensities were not properly represented. The differences were strongly correlated with the rain gauge precipitation, but not with satellite-obtained rainfall. The main conclusion concerns the need for specific local calibration for the study area if PERSIANN-CCS is to be used as an operational tool for the monitoring of extreme meteorological phenomena.
\end{abstract}

Keywords: PERSIANN-CCS; Remotely sensed estimated precipitation; southeast of Spain, Extreme meteorological phenomena

\section{INTRODUCTION}

The monitoring of storms in real time is relevant for the management and prevention of flood risks. The reliability of quantitative precipitation estimations (QPEs) is an important issue in Earth Sciences for management of natural risks [1] and the planning of water resources.

Wide extensions in several parts of the world present networks of meteorological observations that provide suitable information for the management of natural resources and catastrophes. Some such areas receive the water resources necessary for the sustainability of big cities or fragile ecosystems.

Further author information: (Send correspondence to F.C.G.)

F.C.G.: E-mail: fulgencio.canovas@upct.es, Telephone: +34 968327047

S.G.G.: E-mail: sandra.garcia@upct.es, Telephone: +34 968325935

N.K.: E-mail: nkarbala@uci.edu Telephone: -

Remote Sensing for Agriculture, Ecosystems, and Hydrology XIX, edited by

Christopher M. U. Neale, Antonino Maltese, Proc. of SPIE Vol. 10421, 1042109

(c) The Authors. Published under a Creative Commons Attribution CC-BY 3.0 License $\cdot$ doi: 10.1117/12.2278398 
However, in the spatial domain of the present research, the existence of a meteorological network is not sufficient to make an adequate characterization of the spatial distribution of the rainfall because storm events usually present high intensities over a short period of time (a few hours). Hong et al. 2007 [2] make similar observations in their work.

In some cases the QPEs retrieved from remote sensing can constitute an alternative to meteorological rain gauges or, in other cases, these may complement the rain gauge observations. Satellite rainfall estimations (SREs) are valuable continuous registers of rainfall on several time [3] and spatial scales. At present, such satellite rainfall products present three characteristics that would be of potential use in environmental applications: close to global coverage (all longitudes and latitudes between $60^{\circ} \mathrm{N}$ and $60^{\circ} \mathrm{S}$ ); long time series are suitable for climate application (at least 30 years) and, finally, independence from local conditions of the given study area, because the SREs are obtained in real time during extreme meteorological events or other local catastrophes.

Several SRE products are available, such as PERSIANN-CDR (Precipitation Estimation from Remotely Sensed Information using Artificial Neural Networks-Climate Data Record), PERSIANN-CCS (Cloud Classification System), CMORPH (Climate Prediction Center morphing method), TRMM Multi-satellite Precipitation Analysis (TMPA) 3B42RT and 3B42V6 dataset, among others [4]. As well as the more recently released MultiSensor Precipitation Estimate of EUMETSAT (European Organisation for the Exploitation of Meteorological Satellites), or the wide dataset of products from Precipitation Measurement Missions *.

However, the QPEs retrieved from satellite (or SREs) need to be validated by comparison with rainfall measurements of proven reliability, such as those obtained from rain gauges. This is the main objective of the present work, to validate the remote sensing QPEs, PERSIANN-CCS, based on comparisons with those provided by rain gauges networks from SIAM (System of Agricultural Information of Murcia) dataset in the province of Murcia (Region of Murcia in Spanish). Three extreme meteorological events from 2016, 2012 and 2009 were considered in the work.

\section{MATERIALS AND METHODS}

Our main research interest is the validation of a satellite estimation rainfall product with a spatial domain close to global cover for a territory of approximately 11,000 $\mathrm{km}^{2}$ (Region of Murcia). For this, three extreme rainfall events affecting the study area were identified and characterized. The first was registered between 17 and 19 December 2016, and was the most important meteorological episode of the whole year for the Iberian Peninsula. An accumulated total rainfall of $320 \mathrm{~mm}$ for the episode was registered in Sierra Espuña; and $166 \mathrm{~mm}$ in 24 hours was observed in the Torre Pacheco rain gauge. The highest rainfall intensities were registered in Campo of Cartagena and the east coast of the study area, where the rainfall exceeded $40 \mathrm{~mm}$ in one hour in the Torre Pacheco and San Javier rain gauges [5]. Areas close to Mar Menor lagoon, especially the town of Los Alcázares, were severely affected by the storm and the consequent flooding.

The second extreme event studied was registered at the end of September 2012, when the extreme meteorological situation known as gota fría in Spanish combined with high sea water temperatures in the western Mediterranean Sea, originated huge precipitation volumes with high hourly intensity (more than $150 \mathrm{~mm}$ in two hours), flooding several channels (ramblas in Spanish) including the Goñar, Vilerda, Nogalte, Béjar, La Torrecilla, Viznaga and Nogantes-Charcones-Canalejas ramblas and also in the Guadalentín and Almanzora rivers [6].

The third extreme event presented occurred on 27 and 28 September 2009, and affected the Campo of Cartagena area. The daily rainfall of the $28^{\text {th }}$ registered by the corresponding rain gauges was: $160 \mathrm{~mm}$ in La Palma (Cartagena); $115 \mathrm{~mm}$ in La Aljorra (Cartagena); $75 \mathrm{~mm}$ in Fuente Álamo, and $70 \mathrm{~mm}$ in Torre Pacheco. On the the same day, the rainfall registered in more than 20 municipalities of the study area was higher than 30 $\mathrm{mm}$. Substantial flooding was registered in several channels of the study area, for example, the substantial runoff from the Albujón Rambla or the peak flow close to $214 \mathrm{~m}^{3} / \mathrm{s}$ reached in three hours in the Benipila Rambla [7].

As regards QPE, PERSIANN-CCS is a system based on satellite images, wherein satellite images processing and pattern recognition techniques are applied for the automatic classification of several types of cloud in order to estimate the rainfall in each pixel.

\footnotetext{
*https://pmm.nasa.gov
} 
PERSIANN-CCS produces QPE with a time resolution of one hour, a spatial resolution of $0.04^{\circ}$, with near to global coverage (between $60^{\circ} \mathrm{N}$ and $60^{\circ} \mathrm{S}$ ) and a lag time of approximately one hour (near real time), characteristics considered sufficient for hydrological applications at local scale [8]. The PERSIANN-CCS dataset can be freely downloaded from the Center for Hydrometeorology and Remote Sensing of University CaliforniaIrvine (USA).

The SIAM agro-meteorological network consists of more than 45 automatic rain gauges (and others sensors) to estimate reference evapotranspiration and irrigations needs for the crops of Murcia region. The SIAM rain gauges are installed in private agricultural areas where several meteorological variables of agronomic interest are registered, including temperature, relative air humidity, insolation, wind direction, wind speed and rainfall [9].

Several statistics, such as root mean square difference (RMSD or RMSE), bias and the Pearson correlation coefficient were calculated to compare the rainfall values obtained from PERSIANN-CCS with those registered in selected rain gauges of the SIAM network. These statistics were estimated for the whole study area, using the agrarian regionalization proposed by Fernández-González et al. (2013) [10], and for the SIAM rain gauges located in the areas most affected by the highest rainfall intensities. Also, in most cases, corrected statistics were applied, such as those estimated from pairs of values with at least one presenting rainfall greater than zero. This correction is important in the case of extreme meteorological phenomena, where the time steps without rainfall are of no interest. If the number of time steps without rainfall is large, the mean value of the differences is reduced artificially, so that they are not considered.

Firstly, the differences between the rainfall registered by two rain gauges and that corresponding to PERSIANNCCS were analyzed graphically for each event. In the case of the December 2016 event, Fig. 1a presents the recordings made by the AL31 rain gauge located in the Lebor area in the municipality of Totana, with a total accumulated rainfall $(129.7 \mathrm{~mm})$, which is the value closest to the mean recorded by the SIAM network. The second rain gauge considered for the event (TP42 observatory, Fig. 1b) was that located in Torre Blanca area of Torre Pacheco municipality, which registered the highest accumulated rainfall of the SIAM network for the whole event $(285.3 \mathrm{~mm})$. The criteria for selecting the rain gauges in the case of the two other events were the same.

Figs. 1c and 1d present the hyetographs for the MU62 rain gauge (accumulated rainfall equal to $74.60 \mathrm{~mm}$ ), and ML12 rain gauge (accumulated rainfall equal to $128.2 \mathrm{~mm}$ ), respectively. The MU62 observatory is located in La Alberca (Murcia municipality), while ML12 observatory is located in Yechar (Mula municipality).

In the case of the September 2009 extreme event, the hyetographs of AL51 rain gauge $(78.2 \mathrm{~mm}$ ) located in La Egesa area (Librilla municipality) and CA12 rain gauge $(286 \mathrm{~mm}$ ) located La Palma (Cartagena municipality) are presented in Figs. 1e and 1f, respectively.

To complete the analysis, dispersion graphs of SIAM rainfall vs. PERSIANN-CCS rainfall, as well as SIAM rainfall vs. rainfall differences were evaluated. For clarification purposes, only pairs of estimations with both rainfall values higher than zero were considered.

\section{RESULTS}

An analysis of the six hyetographs points to relevant differences between both sources of rainfall values. In the case of the AL31 rain gauge (Fig. 1a), high rainfall intensities between 09:00 and 15:00 h on 17 December 2016 were recorded, and these values were relatively well represented by PERSIANN-CCS although two hours earlier. Nevertheless, the high intensities registered between 06:00 h and 10:00 hours on 18 December 2016 were not captured by PERSIANN-CCS. The hourly RMSD was high $(3.2 \mathrm{~mm})$, and the bias indicated an average underestimation of PERSIANN-CCS of $0.89 \mathrm{~mm} / \mathrm{h}$. In the case of the TP42 rain gauge (Fig. 1b), the observed differences were greater than those corresponding to the above mentioned rain gauge. The extreme intensities registered by this rain gauge should be taken into account: in only two hours (between 21:00 and 22:00 h on 18 December 2016), an accumulated rainfall of $49.3 \mathrm{~mm}$ was registered.

As in the previous case, the highest rainfall intensities of several time steps were not adequately captured by the PERSIANN-CCS dataset. Only in the first hours of the storm, between 08:00 and 12:00 h on 17 December 2016 was the rainfall satisfactorily represented by PERSIANN-CCS. The RMSD was high $(7.37 \mathrm{~mm} / \mathrm{h})$, and 
a) AL31 December 2016

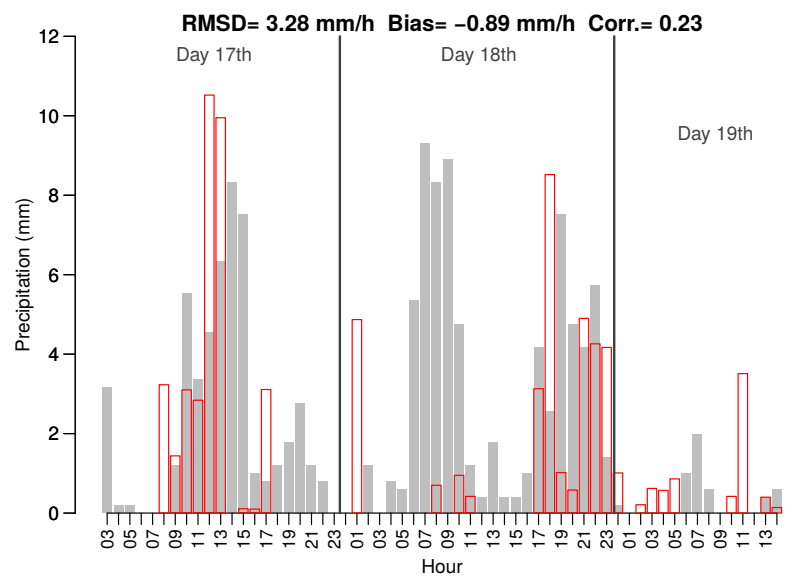

c) MU62 September 2012

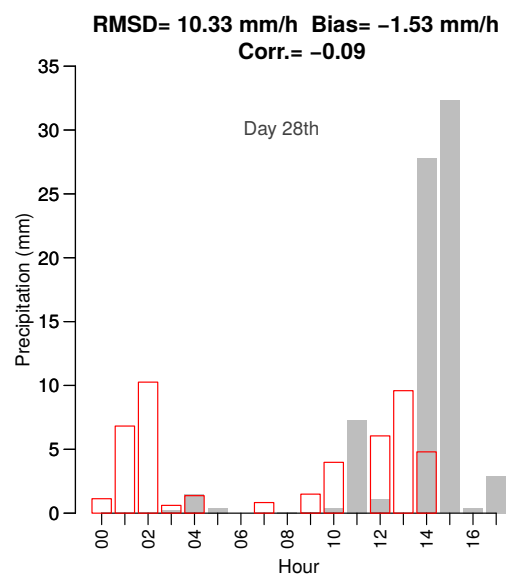

e) AL51 September 2009

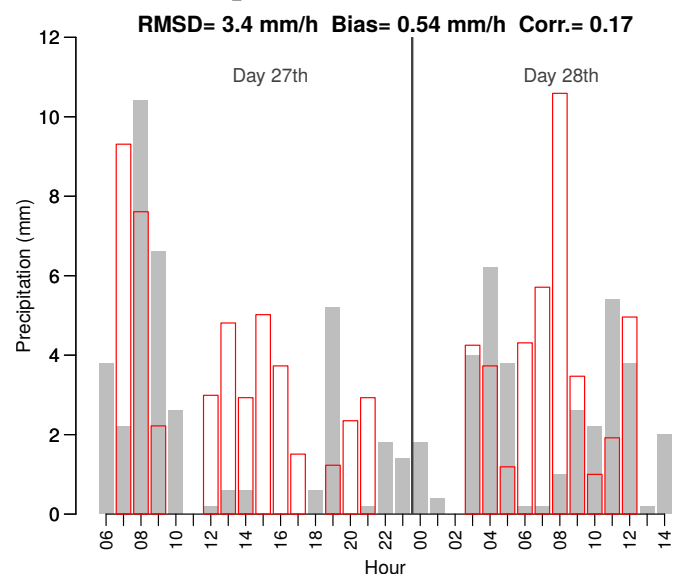

b) TP42 December 2016

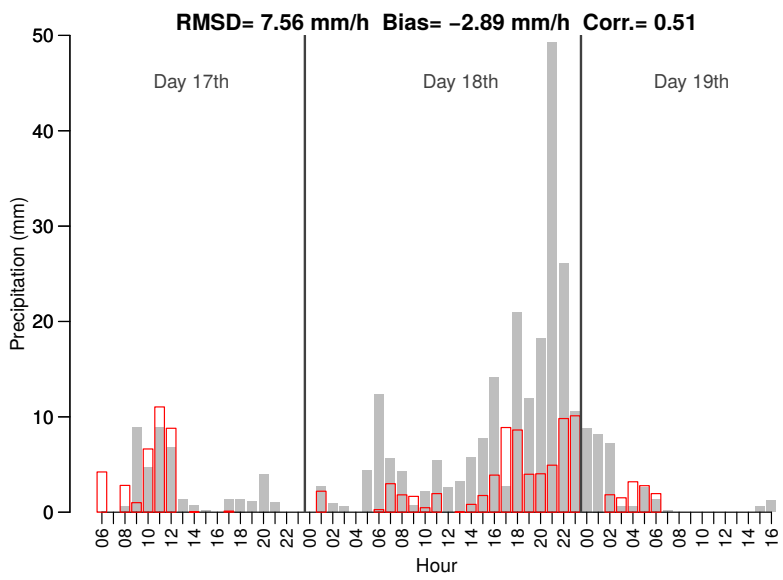

d) ML12 September 2012

RMSD $=15.44 \mathrm{~mm} / \mathrm{h}$ Bias $=-2.69 \mathrm{~mm} / \mathrm{h}$

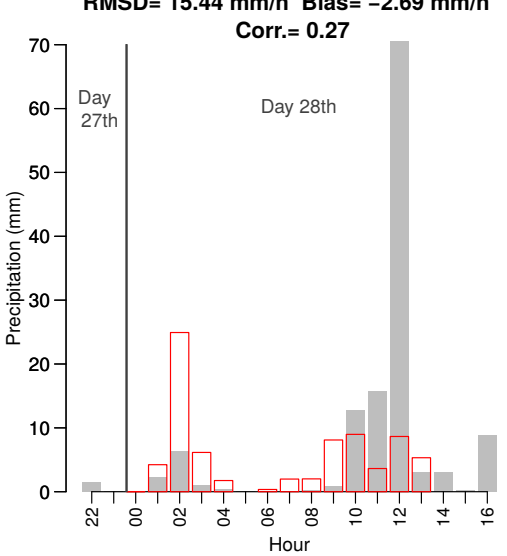

f) CA12 September 2009

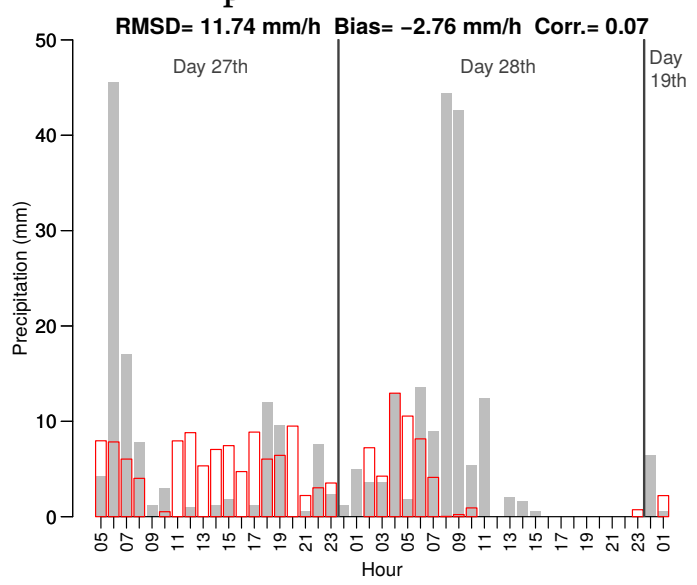

Figure 1. Hyetographs of PERSIANN-CCS and the corresponding rain gauges of SIAM network, and associated statistics. The location of rain gauges is presented in: http://siam.imida.es/apex/fp=101:41:432032925834500 
the bias indicated an underestimation of PERSIANN-CCS compared with the rain gauge registers of the SIAM network.

The hyetographs of the 2012 event (Fig. 1c and d) permit some characteristics of these types of storm to be identified: the concentration of $80 \%(60 \mathrm{~mm})$ of the total quantity of rainfall into only two hours in the MU62 rain gauge, and the concentration of more than $50 \%(76.6 \mathrm{~mm})$ of the accumulated rainfall of the whole event in the ML12 rain gauge. In both cases, the PERSIANN-CCS underestimated the rainfall registered by the corresponding SIAM rain gauges. The RMSD was very high in the case of ML12 rain gauge. In general, the PERSIANN-CCS dataset underestimated the precipitation of the SIAM rain gauges by an average of $1.53 \mathrm{~mm} / \mathrm{h}$ in the case MU62, and $2.69 \mathrm{~mm} / \mathrm{h}$ in the case of ML12.

Similar results were obtained in the analysis of the hyetographs registered for the September 2009 episode (Fig. 1e and 1f). From the hyetographs is observed than the underestimation is not related with any threshold. For several time intervals SIAM rain gauges indicate values of rainfall intensity less than $5 \mathrm{~mm} / \mathrm{h}$, and PERSIANNCCS does not capture any value in some cases, and in other cases it presents very low values of rainfall intensity. Then, the maximum intensity of rainfall satisfactorily estimated from PERSIANN-CCS corresponds to $11 \mathrm{~mm} / \mathrm{h}$.

In the scatter plots of Fig. 2 the PERSIANN-CCS values are represented in the ordinates axis, while the SIAM rain gauges are presented in the abscissas axis. From Fig. 2, a low correlation on the part of both variables is observed. The highest hourly intensities of SIAM rainfall (two values close to $50 \mathrm{~mm}$ in the 2016 episode; two values close to $70 \mathrm{~mm}$ in the 2012 episode; and three values close to $45 \mathrm{~mm}$ in the 2009 episode) are underestimated by PERSIANN-CCS (with values lower than $10 \mathrm{~mm}$ ). By contrast, there were at least three cases of large PERSIANN-CCS overestimations for the 2016 episode (Fig. 2 a), values close to $30 \mathrm{~mm}$ being provided, while SIAM rain gauges registered only $5 \mathrm{~mm}$. Similar cases can be identified for 2012 and 2009 episodes. The

a) December 2016

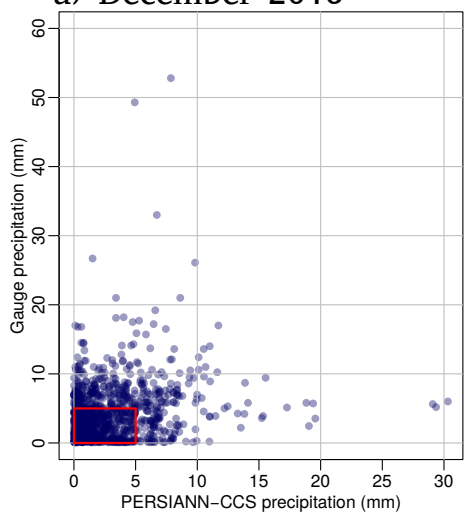

d) December 2016

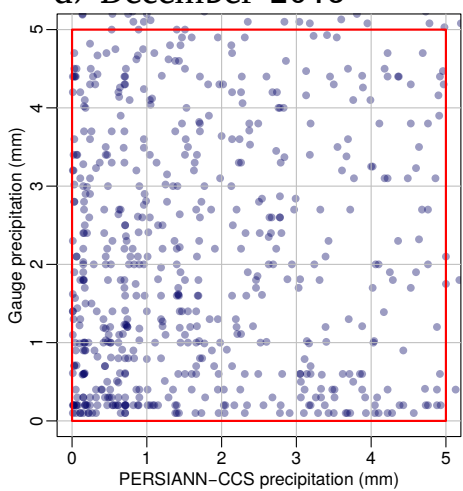

b) September 2012

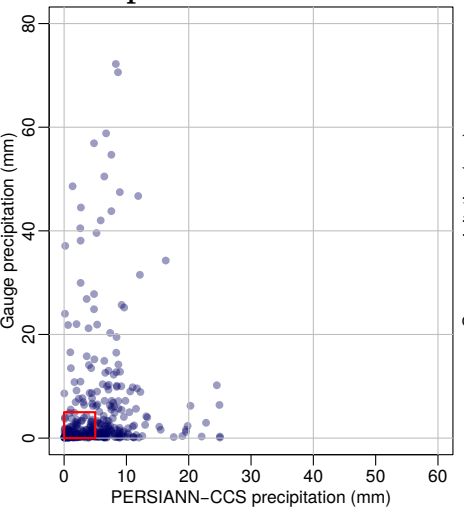

e) September 2012

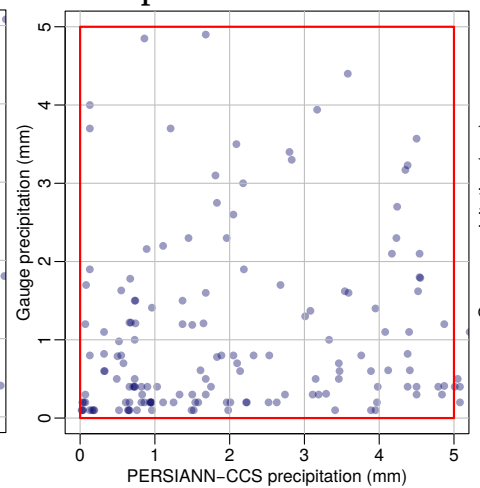

c) September 2009

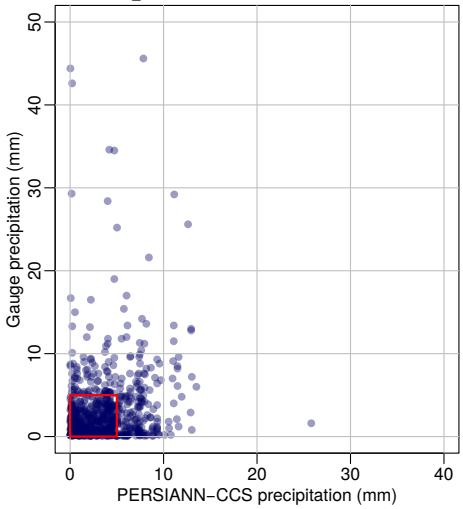

f) September 2009

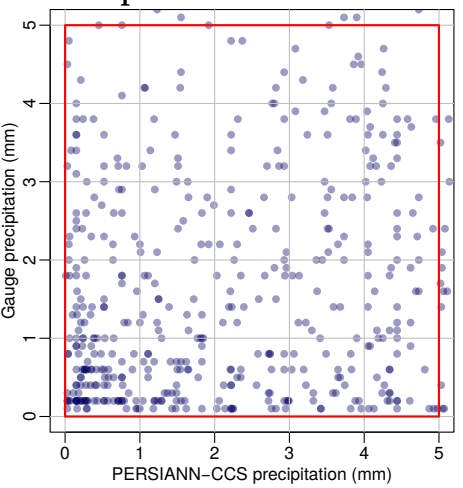

Figure 2. SIAM rainfall vs. PERSIANN-CCS rainfall: a) All cases where both rainfall estimations are greater than zero; and b) Zoom of a). 
a) December 2016

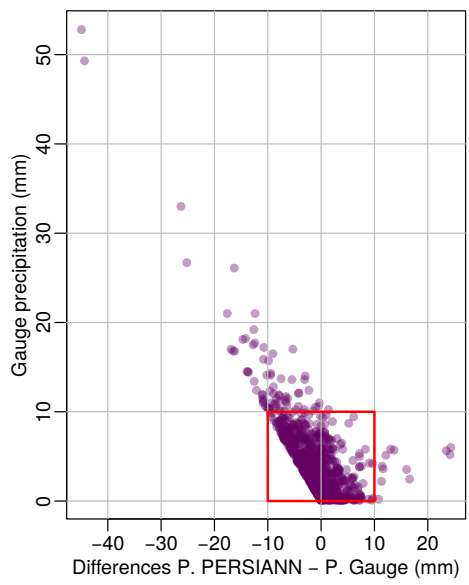

d) December 2016

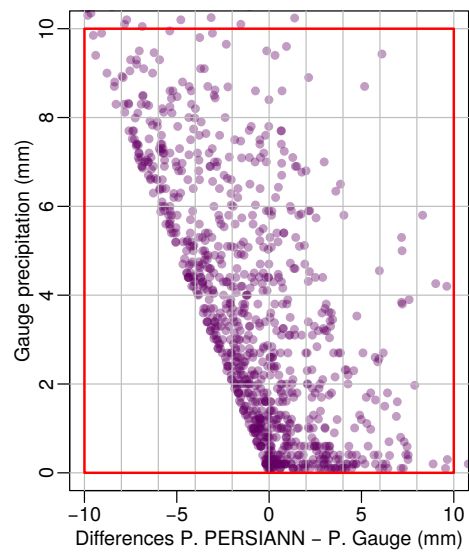

b) September 2012

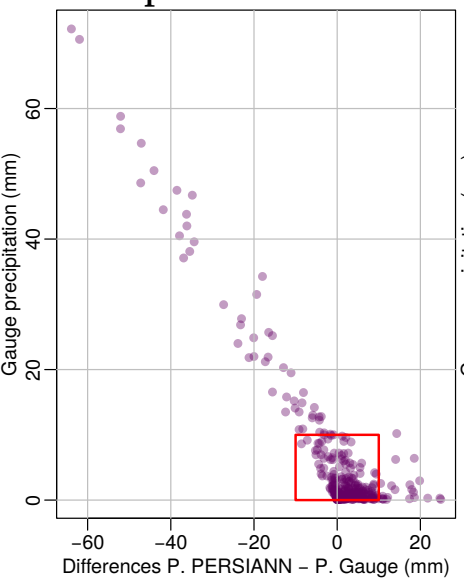

e) September 2012

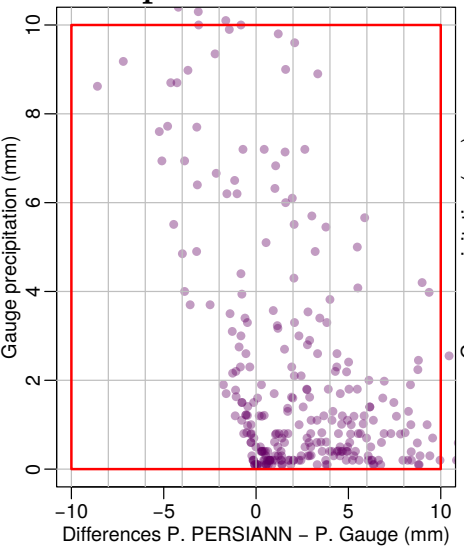

c) September 2009

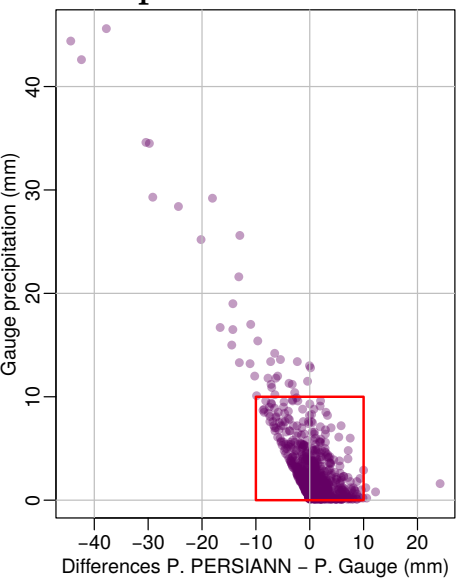

f) September 2009

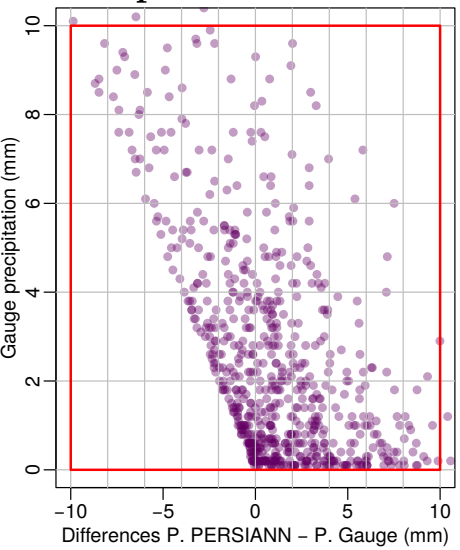

Figure 3. SIAM rainfall vs. rainfall differences between both sources of data: a) All cases where both rainfall estimations are greater than zero; and b) Zoom of a).

maximum value satisfactorily captured by PERSIANN-CCS compared to SIAM rain gauges registers corresponds to $12.5 \mathrm{~mm} / \mathrm{h}$. Higher values of SIAM rainfall were not captured by PERSIANN-CCS, and low values of SIAM rainfall corresponded to very higher PERSIANN-CCS data, as mentioned above.

From the detail scatter plots (Fig. 2 d, e and f), it is clear that neither for low nor for high rainfall values was there good correlation between PERSIANN-CCS and the SIAM rain gauges.

The Fig. 3 presents the scatter plots of SIAM rainfall on the ordinates, and the rainfall differences (PERSIANNCCS minus SIAM) on the abscissas axis, for the three studied events. The correlation is higher than in the previous case, while there is a clear positive linear relation between SIAM rainfall and rainfall differences. In Fig. 3, there are several cases where SIAM rain gauges register rainfall while PERSIANN-CCS presents zero values.

Tab. 1 presents some statistics for the goodness of fit between both estimations (SIAM rain gauges and PERSIANN-CCS). The corrected statistics estimated from all observations are presented, as are the statistics estimated for the agrarian regionalization, and, finally, the statistics for the rain gauges located in the agrarian regionalization most affected by the storm, are presented. In the case of the 2016 and 2009 episodes, the Campo of Cartagena area, and in the case of the 2012 event, the South-west and Valley of Guadalentín River area, were the most affected regions. Considering the overall results (Total value in Tab. 1), the highest RMSD* was for the 2009 episode, with a value of $9.4 \mathrm{~mm} / \mathrm{h}$, while for the 2016 and 2009 episodes the RMSD* was similar at 3.9 and $4.7 \mathrm{~mm} / \mathrm{h}$, respectively. Analyzing the results according to agrarian regionalizations and rain gauge records, 
Table 1. Statistics of goodness of fit between SIAM rain gauge and the corresponding pixels of PERSIANN-CCS, for the three events in the agrarian regionalization of the study area and selected rain gauges. Obs.: Number of observations, RMSD: Root mean square differences, R: Pearson correlation coefficient. The ${ }^{*}$ symbol indicates corrected statistics (page 303). The agrarian regionalization of the Region of Murcia is: NE A.: "North-East area", NW A.: "North-West area", Cent. A.: "Center area", SR A.: "Segura River area", SW A.: "South-West area and Valley of Guadalentín River", and CC A.: "Campo of Cartagena area".

\begin{tabular}{|c|c|c|c|c|c|c|c|c|c|c|c|c|c|c|}
\hline \multicolumn{5}{|c|}{ 2016, 17-19 December } & \multicolumn{5}{|c|}{ 2012, 28 ${ }^{t h}$ September } & \multicolumn{5}{|c|}{$2009,27^{t h}$ and $28^{t h}$, September } \\
\hline Name & Obs.* & RMSD* & Bias* & $\mathbf{R}^{*}$ & Name & Obs.* & RMSD* & Bias* & $\mathbf{R}^{*}$ & Name & Obs.* & RMSD* & Bias* & $\mathbf{R}^{*}$ \\
\hline NE A. & 312 & 2.8 & -0.7 & 0.20 & NE A. & 156 & 8.3 & -0.0 & 0.15 & NE A. & 225 & 2.9 & 0.8 & 0.28 \\
\hline NW A. & 272 & 3.1 & -1.4 & 0.31 & NW A. & 137 & 5.5 & -1.4 & 0.38 & NW A. & 163 & 1.8 & -0.6 & 0.29 \\
\hline Cent. A. & 110 & 3.2 & -1.8 & 0.46 & Cent. A. & 50 & 12.5 & -1.7 & 0.16 & Cent. A. & 84 & 9.6 & -2.0 & -0.08 \\
\hline SR A. & 711 & 3.6 & -1.0 & 0.30 & SR A. & 215 & 8.7 & -0.9 & 0.07 & SR A. & 469 & 3.6 & 0.7 & 0.19 \\
\hline SW A. & 560 & 3.8 & -0.8 & 0.22 & SW A. & 151 & 12.4 & -1.2 & 0.15 & SW A. & 358 & 3.5 & -0.4 & 0.16 \\
\hline CC A. & 494 & 5.1 & -1.5 & 0.38 & CC A. & 132 & 9.7 & -2.5 & -0.14 & CC A. & 398 & 6.4 & -0.4 & 0.16 \\
\hline CA42 & 57 & 4.0 & -0.8 & 0.39 & AL31 & 16 & 11.9 & -0.9 & 0.17 & CA12 & 42 & 12.2 & -3.0 & 0.03 \\
\hline CA52 & 55 & 4.0 & -0.3 & 0.09 & AL41 & 20 & 9.5 & -1.3 & -0.18 & CA42 & 47 & 3.8 & -0.4 & 0.44 \\
\hline CA73 & 46 & 4.1 & -1.3 & 0.22 & AL51 & 19 & 6.9 & -1.5 & 0.27 & CA52 & 43 & 6.7 & -1.5 & 0.42 \\
\hline CA91 & 56 & 4.0 & -1.2 & 0.14 & AL62 & 8 & 6.8 & 1.9 & -0.13 & CA91 & 46 & 4.1 & -1.2 & 0.58 \\
\hline TP22 & 50 & 7.8 & -3.6 & 0.59 & LO11 & 15 & 14.5 & -3.4 & 0.21 & TP22 & 40 & 4.8 & 1.3 & 0.13 \\
\hline ТP42 & 49 & 8.3 & -3.5 & 0.47 & LO21 & 14 & 18.8 & -3.8 & 0.26 & TP42 & 40 & 4.9 & 0.6 & 0.03 \\
\hline TP52 & 51 & 3.7 & -1.3 & 0.58 & LO31 & 8 & 5.4 & 2.4 & -0.13 & TP52 & 48 & 6.5 & 0.4 & 0.05 \\
\hline TP73 & 52 & 2.7 & -0.4 & 0.71 & LO41 & 19 & 7.5 & 1.0 & 0.48 & TP73 & 48 & 5.7 & 0.0 & 0.04 \\
\hline ТР91 & 52 & 5.3 & -1.8 & 0.40 & LO51 & 15 & 12.3 & 0.4 & 0.11 & ТP91 & 44 & 5.6 & 0.4 & -0.01 \\
\hline & & & & & LO61 & 17 & 19.0 & -3.7 & 0.14 & & & & & \\
\hline Total & 3175 & 3.90 & -1.10 & 0.31 & & 841 & 9.40 & -1.2 & 0.13 & & 1697 & 4.7 & -0.0 & 0.17 \\
\hline
\end{tabular}

the differences between the estimations are clearly related with the intensity of the rainfall.

From Tab. 1, the RMSD* for the TP42 rain gauge $(8.3 \mathrm{~mm} / \mathrm{h})$ for the 2016 episode, LO21 rain gauge $(18.8 \mathrm{~mm} / \mathrm{h})$ of 2012 episode, and CA12 rain gauge $(12.2 \mathrm{~mm} / \mathrm{h})$ of 2009 episode, are of note. The corrected bias seems to indicate that, for all analyzed spatial domains, the mean values of PERSIANN-CCS are lower than the corresponding SIAM values. The correlation coefficients are low in almost all cases, although nearly always positive. The Centre area values (0.46) of 2016 episode and North-west area (0.38) of 2012 episode, are
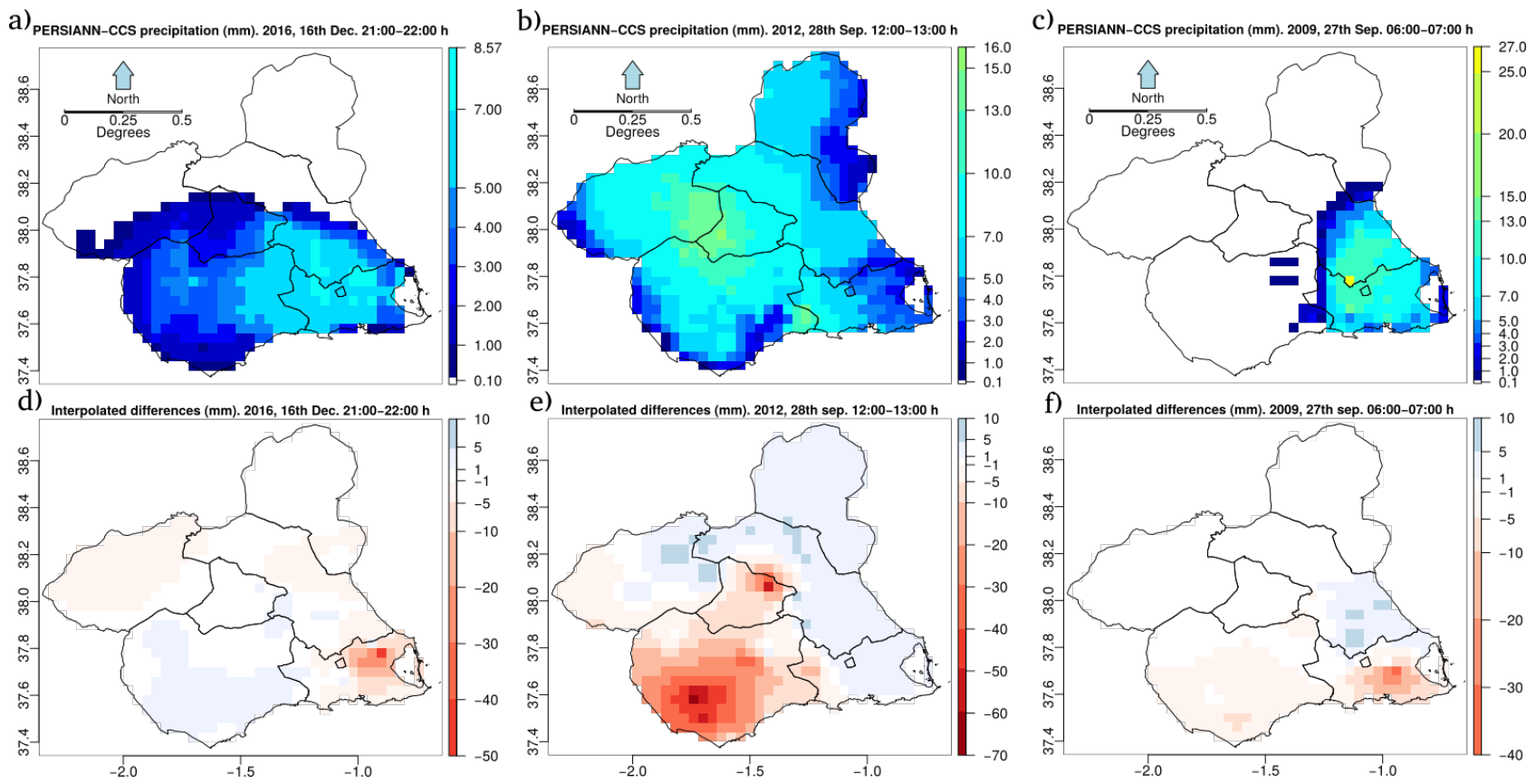

Figure 4. Hourly PERSIANN-CCS precipitation maps for the 2016 (a), 2012 (b) and 2009 (c) events and Inverse Distance Weighted interpolation of the differences for the 2016 (d), 2012 (e) and 2009 (f) events. WGS 84 projection (EPSG 4326 ). 
of note. No correlation coefficient is greater than 0.3 for the 2009 episode. When the rain gauges are analyzed individually, there are some special cases such as the TP73 rain gauge for the 2016 episode (with a correlation coefficient of 0.71 ), or the CA91 rain gauge with a value of 0.58 for the 2009 episode.

Finally, three hourly images of PERSIANN-CCS rainfall are presented (Fig. 4 a, b y c). The Fig. 4 corresponds to the hourly rainfall with the highest intensity registered by the SIAM rain gauge in each event. Fig. $4 \mathrm{~d}$, e, and $\mathrm{f}$, represent the interpolations of rainfall differences, using the inverse distance squared interpolation method.

\section{CONCLUSIONS}

From the results of this work, the QPE PERSIANN-CCS product obtained from satellite images, without any bias correction, does not seem to be applicable to describing extreme rainfall events such as those presented in the south-east of Spain in September 2009, September 2012 and December 2016. These events presented very high return period (close to 500 years), and in general terms the results obtained in the contrast were quite similar to each other. Chen et al. (2014) obtained similar results when three QPEs from satellite were evaluated in contrast to rain gauges over Taiwan [11]. Nevertheless, the potential use of PERSIANN-CCS as complementary information to other sources of rainfall data such as those from rain gauges and radar data, should be remarkable. In the face of contingencies, the applicability and availability of precipitation data obtained from satellite sources, such as PERSIANN-CCS, could be of value since the methods they use to collect information are independent of local conditions or local catastrophes.

A local calibration of PERSIANN-CCS based on automatic rain gauge information would be a good starting point to address the underestimation issue. With a lag time of about 1 hour for both PERSIANN-CCS images and SIAM rain gauges, and a good bias correction process, the new calibrated product could be useful as an operational tool for monitoring extreme rainfall events and feeding hydrological forecasting models.

As futures lines of research, we propose the use of meteorological radars to evaluate the ability of PERSIANNCCS to capture the spatial distribution of extreme storms. Greater efforts should be devoted to assessing the accuracy of the PERSIANN-CCS dataset at other spatial scales, for example at the Iberian Peninsula scale, and analyzing other types of rainfall generation such as frontal systems.

\section{ACKNOWLEDGMENTS}

This work is the result of a postdoctoral contract funded by Saavedra Fajardo programme (Ref. 20023/SF/16) of the Consejería de Educación y Universidades of CARM (Autonomous Community of Murcia Region), by the Fundación Séneca-Agencia de Ciencia y Tecnología de la Región de Murcia. The support and availability of information from the Center for Hydrometeorology and Remote Sensing of University of California-Irvine (USA), and from Instituto Murciano de Investigación y Desarrollo Agrario y Alimentario (IMIDA) of CARM are also acknowledged.

\section{REFERENCES}

[1] Erena, M., López, J., García, P., Caro, M., Belda, F., Palenzuela, J., Toledano, F., Torralba, P., GonzálezBarbera, and G. García-Pintado, J., "Estimación de precipitación combinada radar-pluviómetros y publicación mediante servicios OGC," in [XV Congreso Nacional de Tecnologías de la Información Geográfica. Tecnologías de Información Geográfica en el contexto de Cambio Global], (2012).

[2] Hong, Y., Gochis, D., Cheng, J.-t., Hsu, K.-l., and Sorooshian, S., "Evaluation of PERSIANN-CCS Rainfall Measurement Using the NAME Event Rain Gauge Network," Journal of Hydrometeorology 8, 469-482 (jun 2007).

[3] Ballari, D., Castro, E., and Campozano, L., "Validation of satellite precipitation (TRMM 3b43) in Ecuadorian Coastal Plains, Andean Highlands and Amazonian Rainforest," in [The International Archives of the Photogrammetry, Remote Sensing and Spatial Information Sciences], ISPRS - International Archives of the Photogrammetry, Remote Sensing and Spatial Information Sciences XLI-B8, 305-311, Copernicus GmbH, Prague, Czech Republic (jun 2016). 
[4] Chen, S., Hong, Y., Cao, Q., Kirstetter, P.-E., Gourley, J. J., Qi, Y., Zhang, J., Howard, K., Hu, J., and Wang, J., "Performance evaluation of radar and satellite rainfalls for Typhoon Morakot over Taiwan: Are remote-sensing products ready for gauge denial scenario of extreme events?," Journal of Hydrology 506, 4-13 (dec 2013).

[5] AEMET, "Avance climatológico mensual. Diciembre 2016 en la Región de Murcia," tech. rep. (2017).

[6] Gil Meseguer, E., Pérez Morales, A., and Gómez Espín, J. M., "Precipitaciones y avenidas del 28 de septiembre de 2012 en el cuadrante suroccidental de la cuenca del Segura (municipios de Lorca, Puerto Lumbreras y Pulpí)," Papeles de Geografía (55-56), 75-94 (2012).

[7] Castejón Porcel, G. and Romero Díaz, A., "Inundaciones en la Región de Murcia en los inicios del siglo XXI," Biblio 3W. Revista bibliográfica de Geografía y Ciencias Sociales 19(1102), 1-40 (2014).

[8] Yang, Z., Hsu, K., Sorooshian, S., Xu, X., Braithwaite, D., and Verbist, K. M. J., "Bias adjustment of satellite-based precipitation estimation using gauge observations: A case study in Chile," Journal of Geophysical Research: Atmospheres 121, 3790-3806 (apr 2016).

[9] IMIDA, "Sistema de Información Agrario de Murcia.," tech. rep. (s/f).

[10] Fernández González, J., ed., [Caracterización de las comarcas agrarias de España. Tomo 34. Región de Murcia], Ministerio de Agricultura, Alimentación y Medio Ambiente. Gobierno de España (2013).

[11] Chen, S., Liu, H., You, Y., Mullens, E., Hu, J., Yuan, Y., Huang, M., He, L., Luo, Y., Zeng, X., Tang, G., and Hong, Y., "Evaluation of High-Resolution Precipitation Estimates from Satellites during July 2012 Beijing Flood Event Using Dense Rain Gauge Observations," PLoS ONE 9, e89681 (apr 2014). 